\title{
Call for total ban of production and use of chlorofluorocarbons
}

\section{Washington}

THE administrator of the US Environmental Protection Agency (EPA), Lee Thomas, called last week for the phased total elimination of chlorofluorocarbons (CFCs), used as refrigerants and solvents and in the manufacture of foam packaging, and which are destroying the stratospheric ozone layer. The agency had previously supported the 50 per cent reduction plan set out in the Montreal Protocol negotiated last year between 45 countries, and now ratified by eight. Thomas is still urging all nations to ratify the protocol, but says the "global environmental community must go even further to eliminate these chemicals"

Thomas' announcement, favouring a complete halt to the use and production of CFCs, was based on data presented in a report, commissioned by the EPA, that modelled the environmental consequences of several reduction alternatives. The report stated that even if every country in the world were to participate in the Montreal Protocol, the level of chlorine being released into the atmosphere would nearly triple by the year 2075 . Because CFCs break down slowly in the atmosphere, the report says, their total elimination would still cause chlorine levels to rise for the next six to eight years.

The report also says that methyl chloroform and bromine should be eliminated in order to protect the ozone layer. Methyl chloroform, 'an industrial solvent, is expected to be the major source of chlorine under the Montreal Protocol, because it will be used increasingly as an alternative to CFCs. Bromine, another ozonedepleting halogen, is now used in fire extinguishers. A total ban on CFCs, bromine and methyl chloroform is projected to keep atmospheric levels of halogens stable for the next 100 years.

The Alliance for Responsible CFC Policy, an international group of producers and industrial users of CFCs, also announced its support of a total CFC ban last week. Du Pont, a member of the alliance and one of the major producers of CFC refrigerants, unveiled plans to begin selling a series of alternatives after 1990. Du Pont said this week it is building a plant for the production of HFC-134a a hydrofluorocarbon not containing chlorine - to replace CFC-12, the most widely used refrigerant.
Carol Ezzell

\section{FDA urged to review wonder "smokeless" cigarette for safety}

\section{Boston}

SHOULD a new cigarette described by its manufacturer as "a major technological breakthrough" be subjected to scrutiny by the Food and Drug Administration (FDA)? The new product is due to go on sale in three test markets this week, but a coalition of health associations, including the American Medical Association and the American Cancer Society, have filed a legal petition with FDA, asking the agency to review the product's safety as if it were any other drug.

FDA has traditionally stood aside from the assessment of tobacco products unless manufacturers have made explicit health claims for their product. Regulation so far has been limited to smoking accessories, such as filters meant to reduce intake of nicotine, as well as other 'nicotine delivery products', such as chewing-gum.

R. J. Reynolds tobacco company, which is offering the new cigarettes, called 'Premier', has been careful not to make overt health claims about its product, which is to be advertised as offering "cleaner enjoyment". But there is little doubt that the new product marks a radical departure from previous cigarettes. 'Premiers' have been called "smokeless" cigarettes because they are the first not actually to burn tobacco; instead, tobacco is merely heated with the help of an elaborate internal carbon heating element.

In reality, the high-tech cigarettes are not strictly smokeless: they do provide nicotine-laden vapour which the smoker inhales, but they do not give off ambient smoke at the distal end. This feature is a clear effort to meet public concern about the risks of passive smoking as well as to stem the tobacco industry's declining sales in the United States, which have fallen nearly 2 per cent a year since 1982 .

The petitioning health associations assert that the new cigarettes should receive FDA review in part because Reynolds, in its patent application for the new cigarettes, lists "pharmacologically or physiologically active agents" (including ephedrine and metaproteranal).

Activists in at least one of the test markets, Phoenix, Arizona, say they are considering filing for an injunction against the product until FDA rules on its safety. Says Dr James H. Sammons of the American Medical Association, "We are simply unwilling to accept on faith the new product of an industry that still denies that smoking is unhealthy". Seth Shulman
Du Pont had nuclear reactor problems

\section{Washington}

Details were made public last week of as many as 30 "significant" nuclear reactor incidents that have occurred since 1957 at the Savannah River Plant in South Carolina, a complex of reactors where fuel for nuclear weapons is produced. The most serious incident occurred in 1960 when an attempt to restart one reactor very nearly led to an uncontrolled chain reaction.

The incidents were revealed last week during a joint hearing of the Senate Committee on Government Affairs and the House of Representatives Government Operations Subcommittee on the Environment.

The Savannah River Plant is operated by E. I. du Pont de Nemours \& Company under contract to the US Department of Energy (DoE). Du Pont denies charges that it had made any attempt to hide the nature of these incidents from government officials. A DoE spokesman said that the agency is still reviewing its records to determine whether Du Pont's reports were accurate and complete.

Other incidents revealed in a 1985 memo from a $\mathrm{Du}$ Pont employee include the unexpected power surges (1964); fuel rod melting (1970); and loss of scram capability for up to 40 days (1964).

The hearing was called to investigate the adequacy of DoE's oversight of safety concerns at its reactors, and specifically problems related to the restart of the $P$ reactor at Savannah River. Du Pont has elected not to renew its contract to operate the Savannah River Plant when it expires at the end of March 1989.

Joseph Palca

No fallout likely from Cosmos 1900 Washington

THE nuclear reactor on board the falling Soviet satellite Cosmos 1900 (Nature 335, $199 ; 1988$ ) has been propelled into a high orbit by an automatic safety mechanism, and no longer threatens to fall to Earth. The slightly elliptical 700-kilometre orbit is well beyond the atmosphere, and will be stable for centuries, by which time the radioactivity will have largely subsided. According to Major Alex Mondragon of the US Air Force Space Command in Cheyenne Mountain, Colorado, the ejection of the reactor also sent two fragments of Cosmos 1900 into the atmosphere above the north-west and south-east coasts of Africa, but no sightings of the debris were reported, suggesting that they were small enough to burn up as they descended. Mondragon said that Space Command is certain the nuclear reactor is aboard the piece sent into high orbit, but "can't explain" why.

David Lindley 